\title{
Optimal design of a coproduction system of electricity and hydrogen to manage imbalances resulting from forecast errors in photovoltaic outputs
}

\author{
Ryuji Matsuhashi and Tsuyoshi Yoshioka \\ Department of Electrical Engineering and Information Systems, Graduate School of the University of Tokyo, 113-8656 Tokyo, \\ Japan
}

\begin{abstract}
Renewable power sources are increasing mainly because of economic institutions such as renewable portfolio standard or feed-in tariff program. In Japan, the feed-in tariff program triggered explosive growth of photovoltaic systems because of its high tariff level. Although mass introduction of photovoltaic systems certainly contributes to reduce $\mathrm{CO} 2$ emissions, it causes instability issues in power systems. One of the most serious issues is management of imbalances resulting from forecast errors in photovoltaic outputs. On the other hand, power-to-gas technologies are attracting our attention, since these technologies could convert surplus of renewable energy to other energy carriers. In particular, hydrogen is efficiently produced from electricity using electrolysis. We could use hydrogen to manage the imbalances by the system, in which uncertain parts of photovoltaic outputs are used to produce hydrogen. In this paper, we propose a coproduction system of electricity and hydrogen to reduce the imbalances. For this purpose, a novel mathematical model is developed, in which we determine the structure of the coproduction system with a mixed integer linear programming method. Evaluated results indicated that the coproduction system is economical under appropriate capacity of the electrolyzer.
\end{abstract}

\section{Introduction}

Renewable power sources are increasing in the world, mainly because of economic institutions such as RPS, renewable portfolio standard or FIT, feed-in tariff program. In Japan, PV, photovoltaic systems have been explosively increasing by the FIT program since 2013.

Increase of renewable power sources certainly contributes to $\mathrm{CO}_{2}$ reductions to mitigate climate change. However, mass introduction of renewable power sources is causing serious instability issues; PV outputs are uncertain, causing power system instability. In unit commitments to schedule starts and stops of power plants in advance, operators have to forecast PV outputs in future. But this forecast inevitably includes errors due to uncertainty in future weather conditions. [1] As results, operators have to manage the imbalances resulting from the forecast errors, which are rapidly increasing as the explosive growth of PV systems. Thus management of the imbalances is one of the most serious issues in present power systems.

On the other hand, local power retail companies are increasing nowadays in various countries including Japan. These companies are mainly procuring renewable power sources such as PV systems. It is therefore significant for the local power retail companies to reduce the imbalances by themselves. If they can appropriately manage and compensate the imbalances, that also contributes to the stable management of entire power systems. Regarding analyses in this field, Takahashi [2] developed a mathematical model to operate power systems in the uncertainty. But it is not for local power retail companies, but for large electric utilities.

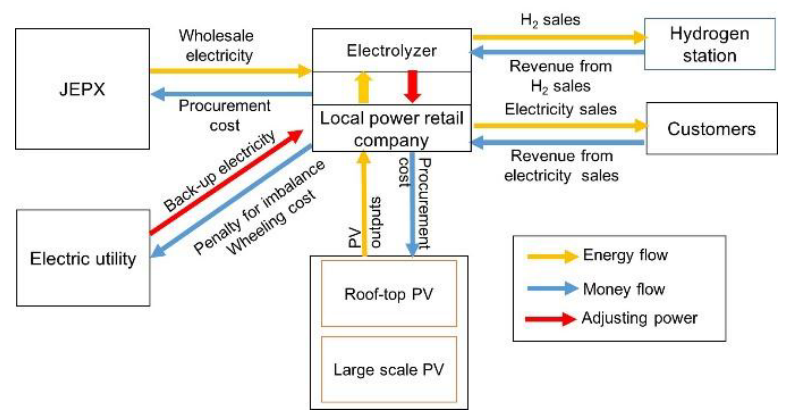

Fig.1 The schematic diagram of the coproduction system

We therefore intend to develop a novel system to manage the imbalances for the local power retail companies. In this respect, power-to-gas technologies are attracting our attention, since these technologies could convert surplus of renewable energy to other energy carriers. In particular, hydrogen is efficiently produced from electricity using electrolysis. We could use hydrogen to manage the imbalances, if uncertain parts of 
PV outputs are used to produce hydrogen. This paper aims at designing a novel coproduction system, in which certain parts of PV outputs are sold as electricity, and uncertain parts of PV outputs are sold as hydrogen. Figure 1 shows the schematic diagram of the coproduction system.

There are past researches utilizing hydrogen to control fluctuating wind power outputs. For instance, the article [3] analyzes the profitability of a wind power plant in combination with a hydrogen storage using decision tree approach, while the article [4] addresses the problem of high imbalance costs for effective trading of wind power, and presents the operation strategy for the minimization of imbalance costs by the use of hydrogen storage. Although there are past researches utilizing hydrogen to control fluctuating wind power outputs, very few papers exist regarding to hydrogen utilization for managing imbalances in a local power retail company, which is investigated in this article.

\section{Methodologies adopted in this article}

This chapter deals with an objective function, constraint functions and other assumptions in the mathematical model for simulating power systems of the evaluated local power retail companies. Table 1 lists the variables used in the objective function and the constraint functions.

Table 1. Variables used in the mathematical model.

\begin{tabular}{|c|l|}
\hline $\mathrm{P}_{\text {tot }}$ & Cash flow of the local power retail company \\
\hline $\mathrm{R}_{\text {tot }}$ & Cash inflow of the local power retail company \\
\hline $\mathrm{C}_{\text {tot }}$ & Cash outflow of the local power retail company \\
\hline$R_{L}$ & Cash inflow from low-voltage consumers \\
\hline$R_{H}$ & Cash inflow from high-voltage consumers \\
\hline$R_{H 2}$ & Cash inflow from hydrogen sales \\
\hline$C_{P V}$ & Procurement cost of electricity from PV \\
\hline$C_{B U}$ & $\begin{array}{l}\text { Procurement cost of electricity based on the } \\
\text { ordinary back-up contract }\end{array}$ \\
\hline$C_{W R}$ & Wheeling cost \\
\hline$C_{M}$ & $\begin{array}{l}\text { Procurement cost of electricity from Japan } \\
\text { Electric Power Exchange }\end{array}$ \\
\hline$C_{E L E}$ & Cost of electrolyzer \\
\hline$C_{I B}$ & Expected cost of penalty for imbalance \\
\hline$R_{L, b a s e}$ & Basic charge by low voltage retail contracts \\
\hline$R_{H, b a s e}$ & Basic charge by high voltage retail contracts \\
\hline$R P_{L}(t)$ & $\begin{array}{l}\text { Amount-based charge by low voltage retail } \\
\text { contracts }\end{array}$ \\
\hline$R P_{H}(t)$ & $\begin{array}{l}\text { Amount-based charge by high voltage retail } \\
\text { contracts }\end{array}$ \\
\hline$P P_{P V}(t)$ & Procurement rate of electricity from PV \\
\hline$C_{B U, b a s e}$ & Basic rate of ordinary back-up contract \\
\hline$P P_{B U}(t)$ & $\begin{array}{l}\text { Procurement rate of electricity based on the } \\
\text { ordinary back-up contract }\end{array}$ \\
\hline$C_{W R, b a s e}$ & Basic charge of wheeling \\
\hline$P T_{H}(t)$ & Amount-based rate of high voltage wheeling \\
\hline$P T_{L}(t)$ & Amount-based rate of low voltage wheeling \\
\hline$P P_{M}(t)$ & $\begin{array}{l}\text { Wholesale rate of electricity in Japan Electric } \\
\text { Power Exchange }\end{array}$ \\
\hline$E_{I B}(t)$ & Penalty rate for imbalances \\
\hline$L_{L}(t)$ & Planned value of low voltage demand \\
\hline$L_{H}(t)$ & Planned value of high voltage demand \\
\hline$G_{P V}(t)$ & Planned value of procuring PV outputs \\
\hline$G_{B U}(t)$ & Planned value of procuring ordinary back-up \\
\hline & \\
\hline & \\
\hline &
\end{tabular}

\begin{tabular}{|c|l|}
\hline & electricity \\
\hline$W R_{H}(t)$ & Planned value of wheeling at high voltage \\
\hline$W R_{L}(t)$ & Planned value of wheeling at low voltage \\
\hline$G_{M}(t)$ & $\begin{array}{l}\text { Planned value of procuring electricity from } \\
\text { JEPX }\end{array}$ \\
\hline$I B_{E X P}(t)$ & Expected value of Imbalance \\
\hline$H_{2}(t)$ & Production amount of hydrogen \\
\hline$P_{H 2}(t)$ & Selling price of hydrogen \\
\hline
\end{tabular}

\subsection{The objective function and the constraint functions in this analysis}

In this section, we explain the objective function and the constraint functions in our numerical model, in which the power system is represented with a mixed integer linear programming method.

In this study, the power system is determined, so that the total profit including revenues and costs takes the maximum as shown in the equation (1).

$$
\text { Maximum } P_{t o t}=R_{t o t}-C_{t o t}
$$

The revenues come from electricity retail for highvoltage customers, low-voltage customers and hydrogen sales, which are shown in the equation (2), (3) and (4), respectively.

$$
\begin{aligned}
& R_{L}=R_{L, \text { base }}+\sum_{t}\left(L_{L}(t) \times R P_{L}(t)\right) \\
& R_{H}=R_{H, \text { base }}+\sum_{t}\left(L_{H}(t) \times R P_{H}(t)\right) \\
& R_{H 2}=\sum_{t}\left(H_{2}(t) \times P_{H 2}(t)\right)
\end{aligned}
$$

The costs consist of procurement of electricity from the contracted solar power generators, wholesale electricity traded in JEPX, Japan Electric Power Exchange, ordinary back-up electricity from Kyushu Electric Utility, the cost of electrolyzer, the wheeling payment and the penalty cost of imbalance as shown in the equation (5).

$$
C_{t o t}=C_{P V}+C_{M}+C_{B U}+C_{W R}+C_{E L E}+C_{I B}
$$

The wheeling costs paid to the Kyushu Electric Utility are also included as shown in the equation (6), since the local power retail company uses the power transmission and the distribution lines owned by the utility.

$$
\begin{aligned}
& C_{W R}=C_{W R, \text { base }}+\sum_{t}\left(W R_{H}(t) \times P T_{H}(t)+W R_{L}(t) \times\right. \\
& \left.P T_{L}(t)\right)
\end{aligned}
$$

The equations (7), (8), (9) and (10) express how to estimate the procurement cost of electricity from the contracted solar power generators, the wholesale electricity traded in JEPX, the ordinary back-up electricity, and the penalty cost of imbalance, respectively.

$$
\begin{aligned}
& C_{P V}=\sum_{t}\left(G_{P V}(t) \times P P_{P V}(t)\right) \\
& C_{M}=\sum_{t}\left(G_{M}(t) \times P P_{M}(t)\right) \\
& C_{B U}=C_{B U, b a s e}+\sum_{t}\left(G_{B U}(t) \times P P_{B U}(t)\right) \\
& C_{I B}=\sum_{t}\left(I B_{E X P}(t) \times P E_{I B}(t)\right)
\end{aligned}
$$


The sum of electricity demand must be equal to the sum of electricity supply in each time slot as shown in the equation (11).

$$
L_{L}(t)+L_{H}(t)=G_{P V}(t)+G_{B U}(t)+G_{M}(t)
$$

\subsection{Imbalances resulting from forecast errors in PV outputs}

In this section, we explain how to deal with errors in forecasting solar power outputs. Takahashi [1] estimated RMSE, root mean square error, in the forecast. According to this article, the probability density function of the forecast errors follows a Laplacian distribution, in which the value of RMSE is approximately $10 \%$ in the one-day-ahead forecast.

Therefore, we assumed the Laplacian distribution as in the equation (12) with $10 \%$ of RMSE in the forecast errors. Then we numerically divided the Laplacian distribution into the following six sets, $\mathrm{S}(1), \mathrm{S}(2), \mathrm{S}(3)$, $\mathrm{S}(4), \mathrm{S}(5), \mathrm{S}(6)$.

$$
\begin{aligned}
& \mathrm{P}(\mathrm{dx})=\frac{1}{\sqrt{2} \sigma} \cdot \mathrm{e}^{-\frac{\sqrt{2}|d x|}{\sigma}} \\
& \mathrm{S}(1)=\{\mathrm{dx} \mid-4.1 \sigma \leq \mathrm{dx} \leq-2.1 \sigma\} \\
& \mathrm{S}(2)=\{\mathrm{dx} \mid-2.1 \sigma \leq \mathrm{dx} \leq-0.8 \sigma\} \\
& \mathrm{S}(3)=\{\mathrm{dx} \mid-0.8 \sigma \leq \mathrm{dx} \leq 0\} \\
& \mathrm{S}(4)=\{\mathrm{dx} \mid \quad 0 \leq \mathrm{dx} \leq 0.8 \sigma\} \\
& \mathrm{S}(5)=\{\mathrm{dx} \mid \quad 0.8 \sigma \leq \mathrm{dx} \leq 2.1 \sigma\} \\
& \mathrm{S}(6)=\{\mathrm{dx} \mid \quad 2.1 \sigma \leq \mathrm{dx} \leq 4.1 \sigma\}
\end{aligned}
$$

Probabilities, for which forecast error, $\mathrm{dx}$ is included in $\mathrm{S}(1), \mathrm{S}(2), \mathrm{S}(3), \mathrm{S}(4), \mathrm{S}(5)$ and $\mathrm{S}(6)$, are assumed to be $2.5 \%, \quad 13.6 \%, 33.9 \%, 33.9 \%, \quad 13.6 \%$ and $2.5 \%$, respectively.

Figure 2 depicts the forecast errors, in which the numbers, 1, 2, 3, 4, 5 and 6 imply the probabilistic areas of $\mathrm{S}(1), \mathrm{S}(2), \mathrm{S}(3), \mathrm{S}(4), \mathrm{S}(5)$ and $\mathrm{S}(6)$, respectively.

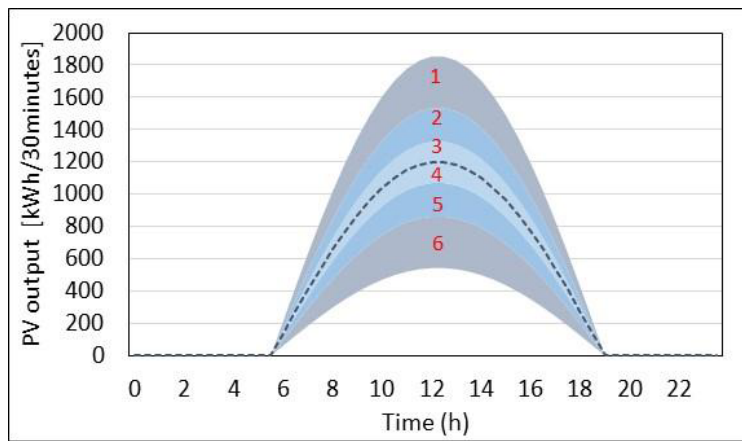

Fig. 2. Errors in forecasting solar power outputs.

Then we determine a baseline for coproduction of electricity and hydrogen as follows. That is, we use PV outputs higher than the baseline to produce hydrogen by electrolysis, and lower than the baseline to sell as electricity. In this article, we set three kinds of baselines, which are the lower limits of $S(4), S(5)$ and $S(6)$. These are defined as baselines 4,5 and 6 , respectively. In chapter 3 , we evaluate the coproduction systems with these baselines as case studies.

\subsection{Assumptions on electricity demand}

Regarding electricity demand, we assumed the high and low voltage demand on the basis of an actual local power retail company. [5]

\subsection{Assumptions on prices of electricity procured and sold by the local power retail company}

Wholesale prices, by which the local power retail company procure electricity, is assumed based on the price traded in JEPX. [6]

On the other hand, we assumed the retail prices of electricity by the local power company referring to actual data. [5]

\section{Evaluated results and discussions}

We first evaluated the relationships between capacities of the electrolyzer and annual cash flows. Figure 3 depicts the cases, in which the baselines of electrolysis are placed on 4, 5 and 6, respectively. Evaluated results show that the cash flow is lowest in the baseline 6 , when the capacity of electrolyzer is 0 . It is natural because, revenue from electricity sales is the least among three cases. As the capacity of the electrolyzer increases, the cash flow in the baseline 6 is drastically improved. Although cash flows in the baselines 4 and 5 are also improved, they are not so sharp as in the baseline 6. As results, the highest cash flow point is acquired by $600 \mathrm{~kW}$ of electrolyzer in the baseline 6 .

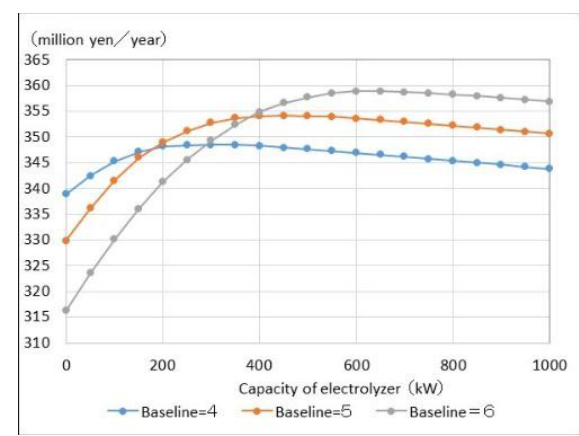

Fig. 3. Relationships between annual cash flows and capacities of electrolyzers.

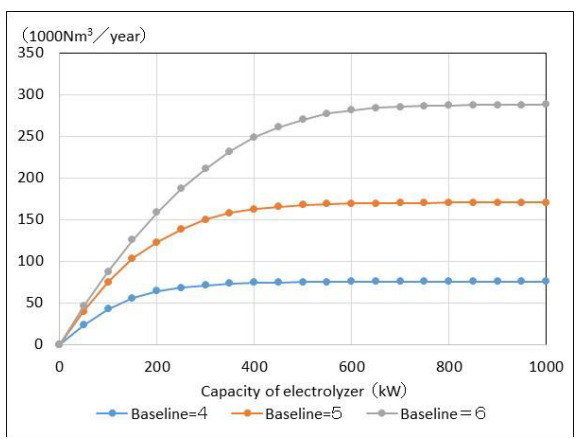

Fig. 4. Relationships between annual revenues from hydrogen sales and capacities of electrolyzers.

Figure 4 depicts relationships between annual revenues from hydrogen sales and capacities of 
electrolyzers, while relationships between annual penalties and the capacities are shown in figure 5. From figure 4, hydrogen sales are shown to saturate after certain capacities of electrolyzers.

In particular, the hydrogen sale in the baseline 6 most drastically increases and then saturates as the capacity increases. From figure 5, imbalances are shown to steeply decrease as capacities of electrolyzers increase. The imbalance cost in the baseline 6 is the highest when the capacity is zero. But it drastically decreases and becomes the least with the capacity of electrolyzer higher than $700 \mathrm{~kW}$.

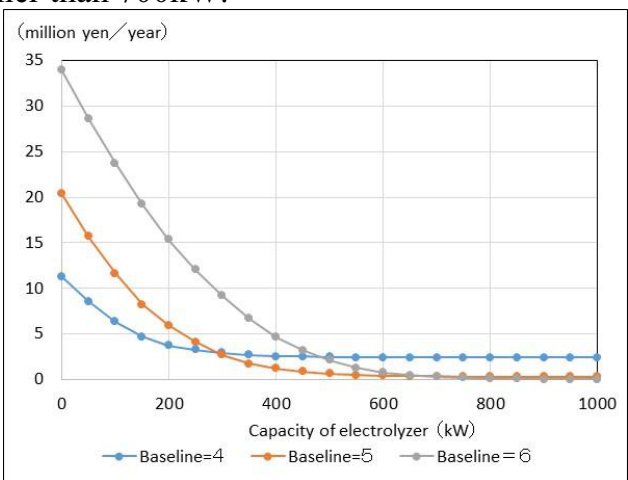

Fig. 5. Relationships between annual penalty costs and capacities of electrolyzers.

Figure 6 shows relationships between factors influencing annual cash flows in the baseline 6 and the capacity of electrolyzer. The hydrogen cost increases and the imbalance cost decreases and then saturate, as the capacity increases. On the other hand, annual cost of the electrolyzer is proportional to the capacity. Taking these trends into consideration, it is natural that the highest cash flow point is acquired in the baseline 6 .

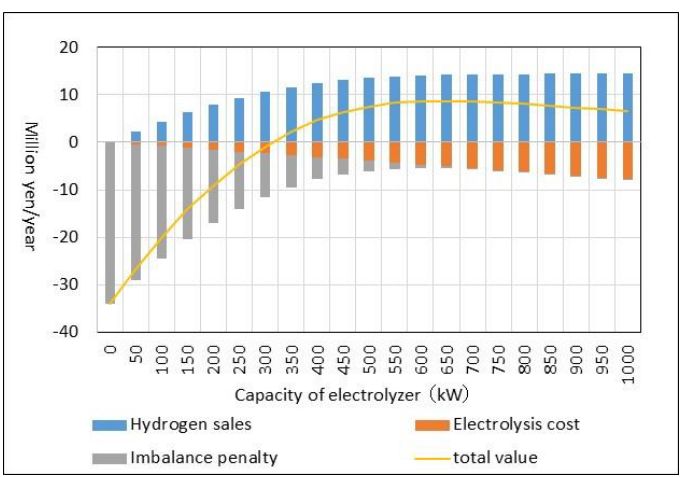

Fig. 6. Relationships between factors influencing annual cash flows in baseline 6 and capacities of electrolyzers.

The above analyses show that the coproduction system of electricity and hydrogen is economical under certain condition.

\section{Conclusion}

Although increase of renewable power sources certainly contributes to decarbonization of energy systems, explosive growth of them threatens stability of power systems. One of the serious issues is how to manage imbalances resulting from forecast errors in solar power generation.

In this paper, we propose a coproduction system of electricity and hydrogen to manage the imbalances. For this purpose, we developed a mathematical model to design the coproduction system dealing with the imbalances. In this model, the imbalances are assumed to be generated probabilistically according to Laplacian distribution. We determine the structure of the coproduction system to maximize the cash flow of a local power retail company, for which the model is represented with a mixed integer linear programming method.

Evaluated results using the above mathematical model indicated that the coproduction system is economical under certain capacities of the electrolyzer and the appropriate baselines of PV outputs, above which hydrogen is produced using electrolysis.

This study was conducted as a part of 'Evaluation and verification of effects to reduce $\mathrm{CO} 2$ emissions utilizing hydrogen in 2018 fiscal year' by Ministry of Environment, Japan.

\section{References}

1. M. Takahashi and R. Matsuhashi, "Area-wide Total Wind and Photovoltaic Power Forecasting Using Multiple Regression Technique and Analysis of Forecast Error Characteristics", Journal of Japan Society of Energy and Resources, 38, 5, 2017.

2. M. Takahashi and R. Matsuhashi, "A Cost Reduction Analysis of Introduction of Battery Energy Storage and Controllable Heat Pump Water Heaters by Operation Planning Model of Power Generation System Considering the Uncertainty in Renewable Power Generation", Transactions on Power and Energy (Journal Sector B), Japan Institute of Electrical Engineering, 137, 12, 2017.

3. Schuster, Martin and Walther, Thomas, Valuation of Combined Wind Power Plant and Hydrogen Storage: A Decision Tree Approach, IEEE Xplore: Proceedings of the 14th International Conference on the European Energy Market (EEM), Dresden 2017.

4. Thakur, T., Goyal, S., Gambhir, J., and Kaur, I. "Optimization of Imbalance Cost for Wind Power Marketability using Hydrogen Storage”, 2008 Joint International Conference on Power System Technology and IEEE Power India Conference, 2008.

5. Miyama Smart Energy. [Online]. Available: http://miyama-se.com/electrical/simmenu/sim-ans-index. [Access date: 2017.11.16]

6. JEPX, JEPX trading information, [Online]. Available: http://www.jepx.org/market/index.html. [Access date: 2017.11.17]. 